Journal of

Applied

Crystallography

ISSN 0021-8898

Editor: Anke R. Kaysser-Pyzalla

\title{
Influence of cold-rolling reduction on retained austenite texture in cold-rolled and intercritically annealed TRIP-assisted steel
}

\author{
E. Emadoddin, A. Akbarzadeh, R. Petrov, L. Kestens and H. Pirgazi
}

J. Appl. Cryst. (2011). 44, 1190-1197

Copyright (C) International Union of Crystallography

Author(s) of this paper may load this reprint on their own web site or institutional repository provided that this cover page is retained. Republication of this article or its storage in electronic databases other than as specified above is not permitted without prior permission in writing from the IUCr.

For further information see http://journals.iucr.org/services/authorrights.html

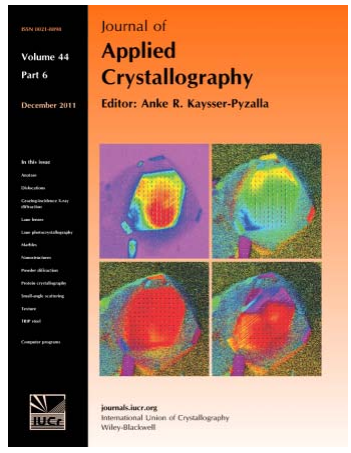

Journal of Applied Crystallography covers a wide range of crystallographic topics from the viewpoints of both techniques and theory. The journal presents papers on the application of crystallographic techniques and on the related apparatus and computer software. For many years, the Journal of Applied Crystallography has been the main vehicle for the publication of small-angle scattering papers and powder diffraction techniques. The journal is the primary place where crystallographic computer program information is published.

Crystallography Journals Online is available from journals.iucr.org 
Journal of

Applied

Crystallography

ISSN 0021-8898

Received 11 July 2011

Accepted 5 October 2011

(C) 2011 International Union of Crystallography

Printed in Singapore - all rights reserved

\section{Influence of cold-rolling reduction on retained austenite texture in cold-rolled and intercritically annealed TRIP-assisted steel}

\author{
E. Emadoddin, ${ }^{\text {a* }}$ A. Akbarzadeh, ${ }^{\text {b }}$ R. Petrov,${ }^{\text {c }}$ L. Kestens ${ }^{\mathrm{c}}$ and H. Pirgazi ${ }^{\mathrm{c}}$

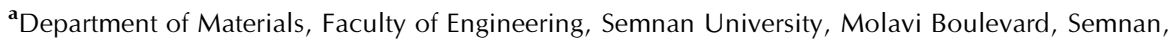 \\ Iran, ${ }^{\mathbf{b}}$ Faculty of Materials Science and Engineering, Sharif University of Technology, Azadi Avenue, \\ Tehran, Iran, and 'Department of Metallurgy and Materials Science, Ghent University, Ghent, \\ Belgium. Correspondence e-mail: emadoddin@semnan.ac.ir
}

The newly developed multiphase transformation-induced plasticity (TRIP) steels are of interest for industrial applications because of their excellent combination of high strength and ductility. Their performance can be successfully controlled by designing an optimum balance in the volume fractions of ferrite, bainite and retained austenite. The characteristics of the retained austenite are considered to be the main key to achieving the desired final properties. Against this background, the effects of retained austenite characteristics, such as volume fraction, carbon concentration, size and shape, on the behaviour of TRIP steels have been studied. The crystallographic orientation of the retained austenite was measured by electron backscattered diffraction (EBSD). The effect of initial cold-rolling reduction on the microtexture development of the retained austenite was studied on an aluminium-containing TRIP steel. The results show that, by increasing the cold-rolling reduction before the final austempering, the main components of the face-centred cubic phase, i.e. copper, brass and Goss, dominate the texture of the retained austenite. In contrast, the copper and Goss components of the retained austenite are absent in the texture of lightly deformed sheets. The features of the preferred orientation of the retained austenite are discussed and explained in terms of the annealing texture of the recrystallized ferrite and bainite.

\section{Introduction}

High-strength transformation-induced plasticity (TRIP)assisted steels have been developed for innovative design applications in the automotive industry (Takahashi, 2003; De Cooman, 2004; De Cooman et al., 2004). Multiphase TRIPassisted steels contain ferrite, bainite or martensite and approximately $5-15 \%$ retained austenite. Transformation of the retained austenite to martensite by straining not only increases the work-hardening capacity of the steel but also provides good ductility and stretching formability during forming operations (Sugimoto, Iida et al., 2000; Sugimoto, Sakaguchi et al., 2000; Sugimoto et al., 2002; Lee, Kim, Song \& Lee, 2002; Lee et al., 2004) by postponing strain localization. This not only improves the performance of the steel during the forming operation but also positively affects the final operational conditions by improving the strength and shockabsorption potential. Such a suitable combination of properties can only be achieved by appropriately engineering the microstructure of the final product, which, in turn, requires a detailed understanding of the transformation behaviour of the retained austenite under strain.
Retained austenite is an important microstructural constituent of TRIP steels. The volume fraction, distribution and transformation characteristics of the retained austenite directly affect the TRIP behaviour. The optimum amount of retained austenite with accurately tuned transformation characteristics (i.e. control of its stability) is of crucial importance for the forming behaviour of the steel (Sugimoto, Iida et al., 2000; Sugimoto et al., 2002; Lee, Kim, Song \& Lee, 2002). Processing parameters such as chemical composition, intercritical annealing temperature, bainitic holding temperature and time have been widely studied in TRIP-assisted steel sheets for industrial applications (Baik et al., 2001; Girault et al., 1999; Saleh \& Priestner, 2001; Wang \& Hsu, 2005; Kim et $a l ., 2001)$. A controlled rolling temperature and strain path are also important thermomechanical conditions in the manufacturing process of TRIP steels (Skalova et al., 2006; Timokhina et al., 2003; Ryu et al., 2002). In this way, the size, shape, volume fraction and carbon concentration of the retained austenite and the types of surrounding phase are optimized (Ryu et al., 2002; Basuki \& Aernoudt, 1999; Eberle et al., 1999; Luo et al., 2003). In order to obtain maximum benefit from the TRIP effect, processing conditions such as temperature, strain 
Table 1

The chemical composition and equilibrium critical temperatures of the steel.

\begin{tabular}{|c|c|c|c|c|c|c|c|}
\hline \multicolumn{6}{|c|}{ Chemical composition (wt\%) } & \multicolumn{2}{|c|}{ Critical temperatures (K) } \\
\hline $\mathrm{C}$ & $\mathrm{Mn}$ & $\mathrm{Si}$ & $\mathrm{P}$ & $S$ & $\mathrm{Al}$ & $\overline{A_{c 1}}$ & $\mathrm{~A}_{\mathrm{c} 3}$ \\
\hline 0.27 & 1.48 & 0.28 & 0.015 & 0.001 & 1.08 & 1019 & 1243 \\
\hline
\end{tabular}

rate, strain path and stress state during the forming operation also need to be taken into consideration (De Cooman, 2004; Pyshmintsev et al., 2002; Furnémont et al., 2003).

The effect of retained austenite characteristics on TRIP behaviour has been extensively studied (De Cooman, 2004; De Cooman et al., 2004; De Meyer et al., 1999), and the available data and results are sufficient to predict its influence on the mechanical properties and formability of TRIP-assisted steel sheets. However, there has not yet been a systematic study of the microtexture of retained austenite and its orientation relationship with respect to other phases. The texture of the retained austenite might affect its stability during the forming processes. In the present study, the transformation stability of individual texture components of the retained austenite phase of a TRIP-assisted steel after thermomechanical processing was examined using orientation imaging microscopy (OIM), also known as electron backscatter diffraction (EBSD).

In this research, a recently developed commercial grade Alcontaining TRIP-assisted steel was investigated instead of a conventional grade Si-alloyed TRIP steel. The effect of initial cold-rolling reduction on microtexture development in the retained austenite and the associated formation mechanisms are discussed.

\section{Experimental}

An aluminium-containing TRIP-assisted steel was employed in this study. The chemical composition and critical temperatures of this steel are shown in Table 1. The critical temperatures were measured by a dilatometry test under heating and cooling conditions of $5 \mathrm{~K} \mathrm{~min}{ }^{-1}$ on a cylindrical sample, which was cut and machined from the as-received hot-rolled material.

Hot rolling of the initial block was carried out to a thickness of 2.7 or $3.7 \mathrm{~mm}$. The final rolling temperature was $1223 \mathrm{~K}$, and after rolling the sheets were air-cooled to room temperature. After removal of the surface oxide layer, the 2.7 or $3.7 \mathrm{~mm}$-thick hot bands were cold rolled to $0.6 \mathrm{~mm}$ sheets with $65 \%$ (A1) and $84 \%$ reduction (A3) in thickness, respectively. Table 2 displays the variations in the heat treatment parameters that were used in this research. One group of A1 and A3 cold-rolled sheets was intercritically annealed at $1083 \mathrm{~K}$ for $5 \mathrm{~min}$, quenched to $672 \mathrm{~K}$ in a salt bath for $3 \mathrm{~min}$ and then air-cooled to room temperature (this regime of heat treatment was denominated T1). Another group of samples was annealed at $1033 \mathrm{~K}$ (close to the $A_{\mathrm{c} 1}$ temperature, i.e. the temperature at which austenite begins to form during heating) (regime T2) to investigate the recrystallization behaviour of
Table 2

The processing parameters of the thermomechanical experiments.

\begin{tabular}{llll}
\hline Sample code & $\begin{array}{l}\text { Degree of } \\
\text { cold-rolling } \\
\text { reduction }(\%)\end{array}$ & $\begin{array}{l}\text { Annealing } \\
\text { temperature and } \\
\text { time }(\mathrm{K}, \mathrm{min})\end{array}$ & $\begin{array}{l}\text { Austempering } \\
\text { temperature and } \\
\text { time }(\mathrm{K}, \mathrm{min})\end{array}$ \\
\hline A1T1 & 65 & 1083,5 & 673,3 \\
A3T1 & 84 & 1083,5 & 673,3 \\
A1T2 & 65 & 1033,5 & 673,3 \\
A3T2 & 84 & 1033,5 & 673,3 \\
\hline
\end{tabular}

the deformed ferrite matrix. It is believed that at this temperature the recrystallization of ferrite will be complete, while the transformation to austenite will be negligible.

All EBSD studies were executed in the rolling direction/ normal direction (RD-ND) section of the annealed sheets after appropriate sample preparation, which included mechanical grinding and polishing up to $1 \mu \mathrm{m}$ diamond paste, followed by electropolishing with A2 Struers electrolyte at room temperature. The EBSD measurements were carried out on the above-mentioned samples using an FEI XL30 ESEM equipped with an $\mathrm{LaB}_{6}$ filament operated at an acceleration voltage of $25 \mathrm{kV}$. The EBSD patterns were acquired using the TSL OIM software (TexSem Laboratories, 2010) attached to the ESEM. The samples were mapped with a step size of $80 \mathrm{~nm}$ on a hexagonal scan grid at a magnification of $4000 \times$. Finally, TSL OIM (Version 4.6) was used for post-processing the orientation data.

The amount of retained austenite was measured by X-ray diffraction (Mo $K \alpha$ radiation). The intensities $\left(I_{\gamma}\right)$ of the $(220)_{\gamma}$ and $(311)_{\gamma}$ austenite, and the $(211)_{\alpha}$ ferrite peaks $\left(I_{\alpha}\right)$, were measured at room temperature and, from their averaged intensities, the fraction of retained austenite $\left(f_{\gamma_{R}}\right)$ was calculated using the following equation (Lee, Kim, Oh \& Lee, 2002; Miller, 1964, 1968):

$$
f_{\gamma_{R}}=\frac{1.4 I_{\gamma}}{I_{\alpha}+1.4 I_{\gamma}} .
$$

\section{Results and discussion}

The orientation distribution of the retained austenite phase, as derived from the microtexture of this phase, was calculated by and is presented as orientation distribution functions (ODFs). Fig. 1 shows the ODFs of the retained austenite phase after cold rolling to reductions of $65 \%$ (A1T1, Fig. 1a) and $84 \%$ (A3T1, Fig. $1 b$ ), followed by subsequent annealing at $1083 \mathrm{~K}$.

The retained austenite texture of the $65 \%$ cold-rolled sample (A1T1) contains the brass component $(\{011\}\langle 211\rangle)$ and extends along the $\beta$ fibre towards the $\mathrm{S}$ component $(\{123\}\langle 634\rangle)$. The so-called $\mathrm{P}$ texture component $(\{011\}\langle 122\rangle)$ is observed in the texture of the retained austenite, whereas the copper, Goss and cube components are not present ( $c f$. Fig. 1a). Indeed, these components of the face-centred cubic (f.c.c.) texture are observed in deformed austenite in carbon 
steels (Verlinden et al., 2001; Hutchinson et al., 1998; Regle et al., 2004).

The TRIP steel after $84 \%$ cold rolling and heat treatment shows a different texture. The intensity of the texture components is weaker than at the lower cold reduction (A1T1). Moreover, under the A3T1 conditions, the copper $(\{112\}\langle 111\rangle)$, Goss $(\{011\}\langle 100\rangle)$ and cube $(\{001\}\langle 100\rangle)$ components, which are not observed under the former conditions, have developed as local texture components of the retained austenite (Fig. 1b), whereas the intensity of the $\mathrm{P}$ component has decreased slightly in comparison with the ODF of Fig. 1(a). In fact, all texture components appear with similar intensities in the A3T1 sample.

The general mechanism of recrystallization and phase transformation in cold-rolled TRIP-assisted steels has been well studied by other researchers (Petrov et al., 2001; Huang et al., 2004). In the initial heating stage of the annealing treatment, the recrystallization of the deformed ferrite will be completed, while spherodization of the pearlitic cementite takes place by a concurrent diffusion process. In the second stage of the annealing treatment, during soaking above the $A_{\mathrm{c} 1}$ temperature, the austenite nucleates at the grain boundaries and near the carbon-rich regions. The existence of retained austenite (about $8.6 \%$ ) in the initial hot band is proved by X-ray diffraction (Fig. 2a). This austenite transforms to martensite during cold rolling, which is proved by the disappearance of the (220) and (311) austenite peaks from the X-ray diffraction patterns (Figs. $2 b$ and $2 c$ ). Accordingly, it is expected that the mechanism of recrystallization and phase transformation is similar to that reported by Petrov et al. (2001).

In this work, it is observed that the intercritical annealing of a cold-rolled sheet at $1083 \mathrm{~K}$ for $5 \mathrm{~min}$ results in complete recrystallization of the deformed ferrite coexisting with the austenite phase.

It has been reported elsewhere that, by increasing the cold-rolling reduction, an intensive ferrite $\gamma$-fibre texture $[(111) / / \mathrm{ND}]$ is developed in TRIP steels (Emadoddin \& Akbarzadeh, 2005), which is similar to the texture developed in other body-centred cubic (b.c.c.) materials (Walentek et al., 2005; Ray \& Jonas, 1990). Although the definition of the $\gamma$-fibre components of the deformed material decreases during the annealing process (Petrov et al., 2001; Samajdar et al., 1998; De Meyer et al., 2001; Zaefferer et al., 2004), it could be concluded that, when the TRIP steel is annealed at a constant temperature, stronger recrystallization texture components are formed in the vicinity of the $\gamma$-fibre texture when an increased rolling strain is imposed prior to annealing.

By annealing the cold-rolled samples at $1033 \mathrm{~K}$ (A1T2 and A3T2; Table 2), only the recrystallization of the deformed ferrite grains is completed.

Figure 1

(b)

ODFs displaying the texture of the retained austenite that forms after intercritical annealing at $1083 \mathrm{~K}$ and austempering at $673 \mathrm{~K}$ in $(a) 65 \%$ and $(b) 84 \%$ cold-rolled sheets (EBSD data). 
After rapid cooling, it is expected that the texture of the recrystallized ferrite will not change. Also, with regard to the onset temperature of the ferrite-to-austenite transition, the volume fraction of the austenite phase at this temperature would be negligibly small, and thus the texture change of the ferrite grains can be neglected. Hence, the EBSD measurements on the samples at room temperature will reflect the preferred orientations of the recrystallized ferrite grains from the intercritical region.

The microtexture of the ferrite grains after recrystallization as determined by EBSD is shown in Fig. 3. Different initial cold-rolling reductions result in different texture components and intensities in the recrystallized material. After annealing,
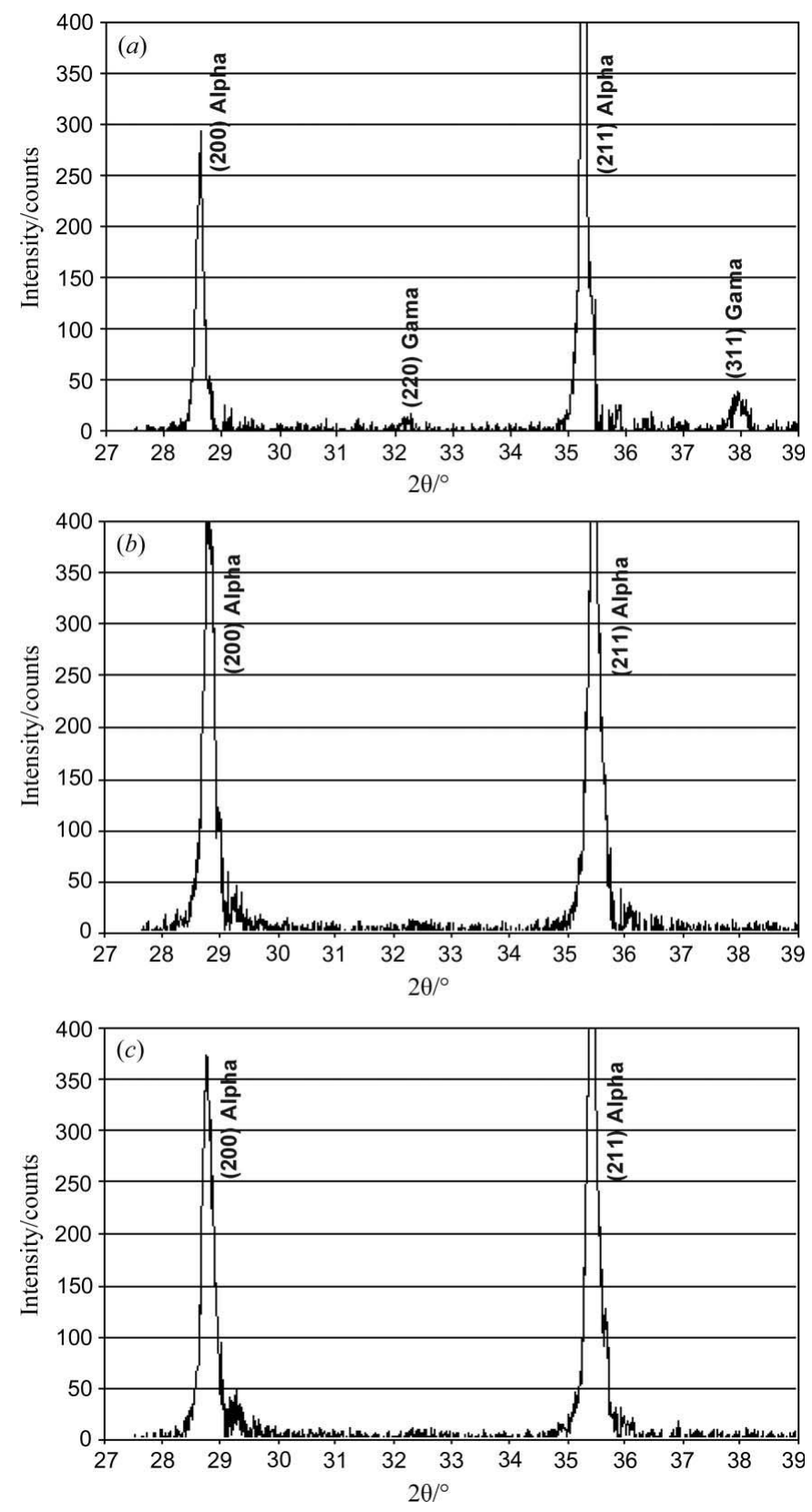

Figure 2

X-ray diffraction patterns of $(a)$ the hot-rolled sample, $(b)$ the $65 \%$ coldrolled sample and $(c)$ the $84 \%$ cold-rolled sample. the more deformed ( $84 \%$ cold-rolling reduction) sample shows a strong rotated-cube $(\{001\}\langle 110\rangle)$ texture component with an intensity of 4.5 times random, and an $\left\{\begin{array}{lll}8 & 8 & 11\end{array}\right\}\langle 110\rangle$ texture component with an intensity of 2.5 times random. The latter component is rotated approximately $10^{\circ}$ away from the $\{111\}\langle 011\rangle$ component along the $\alpha$-fibre direction. Recrystallized ferrite in the $65 \%$ cold-rolled sheets displays the highest intensity of 4.5 on the $\{883\}\langle 258\rangle$ texture component and a set of low-intensity texture components aligned along the so-called transformation fibre (Akbarzadeh, 1994) (or ferrite $\beta$ fibre). Therefore, it could be supposed that, because of the low reduction, the typical $\{111\}\langle u v w\rangle$ recrystallization texture is not able to develop in this case and the ferrite simply reverts back to the hot band texture. Similar texture components have been experimentally observed and discussed by others (Hutchinson et al., 1998; Petrov et al., 2001; Samajdar et al., 1998; De Meyer et al., 2001).

As explained earlier, by reheating the TRIP steel to $1083 \mathrm{~K}$, the austenite nucleates more frequently at the recrystallized ferrite grain boundaries in the carbon-rich regions of the microstructure. It has been shown that the $\{111\}\langle 110\rangle$ ferrite grains may be preferentially selected for transformation and are the first to be consumed by the newly formed austenite grains (Inagaki, 1998). Hence, the intensity of this component in the recrystallized ferrite would decrease after the $\alpha$-to- $\gamma$ transformation (Petrov et al., 2001). The measured ferrite texture at $1083 \mathrm{~K}$ (Fig. 4) and comparison with the texture

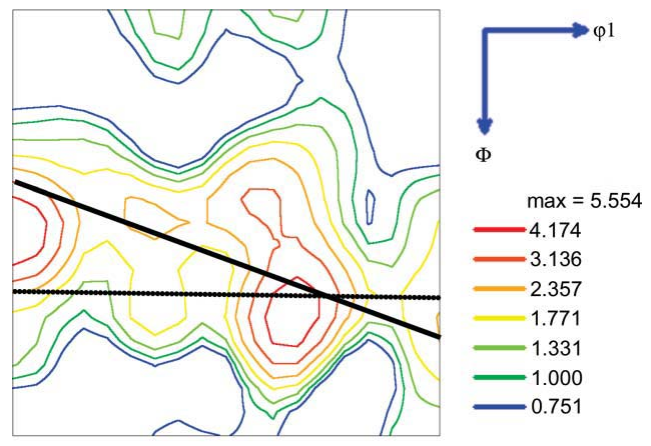

(a)

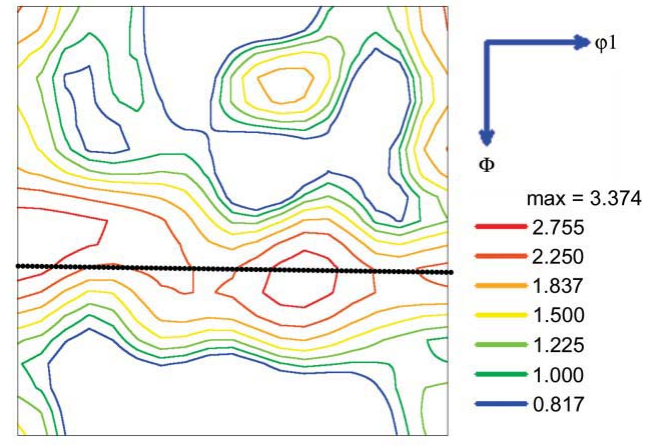

(b)

Figure 3

$\varphi_{2}=45^{\circ}$ sections of ODFs representing the texture components of recrystallized ferrite. TRIP steels with initial cold-rolling reductions of $(a)$ $65 \%$ and $(b) 84 \%$ were annealed at $1033 \mathrm{~K}$ for $5 \mathrm{~min}$. The thick solid line shows the position of the transformation fibres (ferrite $\beta$ fibres) and the dashed lines the positions of the $\gamma$ (or ND) fibres. 
components of ferrite at $1033 \mathrm{~K}$ (Fig. 3) show that ferrite grains with $\gamma$-fibre components are preferentially transformed to austenite during heating within the intercritical region. It is also believed that the Kurdjumov-Sachs (KS) orientation relationship is more probable and has been confirmed in the $\alpha$-to- $\gamma$ transformation of C-Mn-Si TRIP-assisted steel (Zaefferer et al., 2004).

Considering the orientation relationship between the parent phase $(\alpha)$ and the product phase $(\gamma)$ on heating, and knowing the preferred orientation of recrystallized ferrite (Fig. 3), the austenite texture in the intercritical region can be predicted and compared with the measured texture of the residual austenite, assuming that the latter does not change upon quenching to room temperature. By making this assumption, the effect of solute carbon in retained austenite on the development of the crystallographic texture is ignored. It may not be excluded, though, that in a commercial TRIP steel annealing treatment the austenite stabilization, which is a result of bainite formation during the bainite holding stage of the annealing cycle, is orientation.

The observed texture components of the austenite phase for the highly deformed sample are slightly different from those observed in the lightly deformed samples. The strong rotated cube and the $\{111\}\langle 011\rangle$ components of the recrystallized ferrite grains in the $84 \%$ cold-rolled sample give rise to copper, brass and Goss texture components in the austenite. Conversely, in the lightly deformed sample (A1T1), the

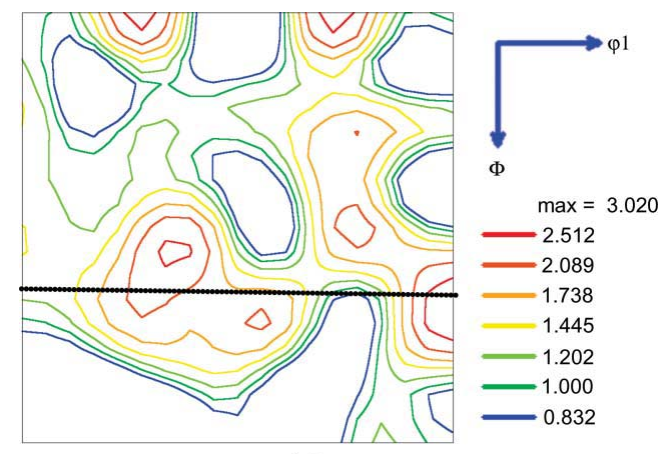

(a)

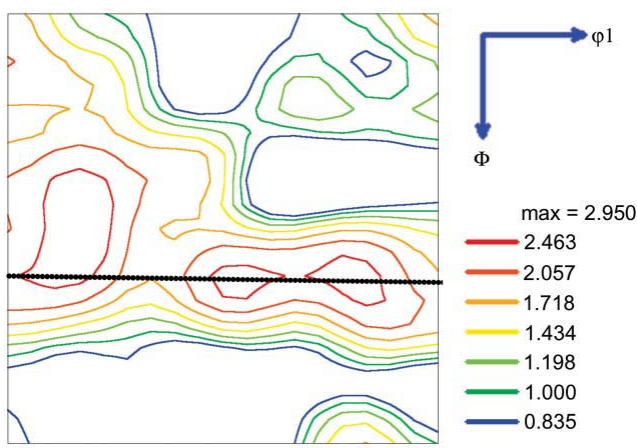

(b)

Figure 4

$\varphi_{2}=45^{\circ}$ sections of ODFs representing the texture components of ferrite in the final microstructures of $(a)$ the A1T1 and $(b)$ the A3T1 TRIP steel samples. This texture shows the ferrite grain texture components after intercritical annealing. The dashed lines indicate the $\gamma$-fibre positions on the ODFs. weaker near $\{001\}\langle 100\rangle$ and $\{554\}\langle 225\rangle$ components of the recrystallized ferrite grains (Fig. $3 a$ ) essentially develop brass, weak Goss and copper components in the transformed austenite. Moreover, it seems that the brass component in the final retained austenite texture (Fig. 1a), assuming that it did not change during the transformation of austenite to bainitic ferrite, can originate from the recrystallized $\{554\}\langle 225\rangle$ component of ferrite during austenitization. Fig. 5 presents the predicted orientations of high-temperature austenite, which can be obtained by transformation of $\{554\}\langle 225\rangle$-oriented ferrite grains, assuming that the $\alpha$-to- $\gamma$ transformation obeys the KS orientation relationship and without variant selection. Although the measurement of the austenite texture at high temperature was not possible, all of the predicted orientations of the austenite can be confirmed by the retained austenite texture (Fig. 1).

The preferred orientations of austenite that transform to bainite are also important for the formation of the final texture of the retained austenite and should be considered separately. Those austenite orientations which preferentially transform to bainite are expected to be absent from the final texture of the retained austenite. This situation is valid when

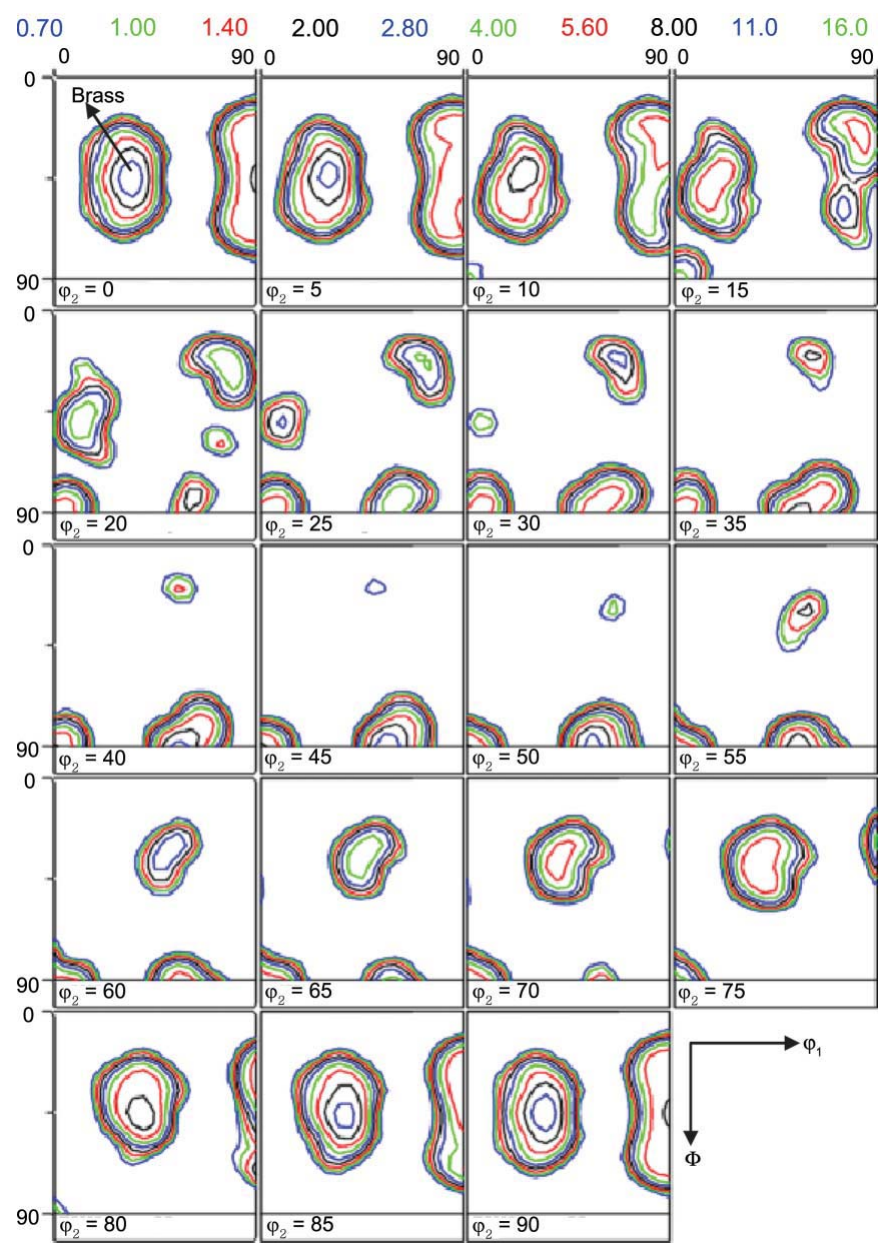

Figure 5

A model of the $\gamma$-phase texture after KS transformation of a single $\{554\}\langle 225\rangle$ b.c.c. orientation to the $\gamma$ phase. One of the products is brass and another is rotated Goss. 


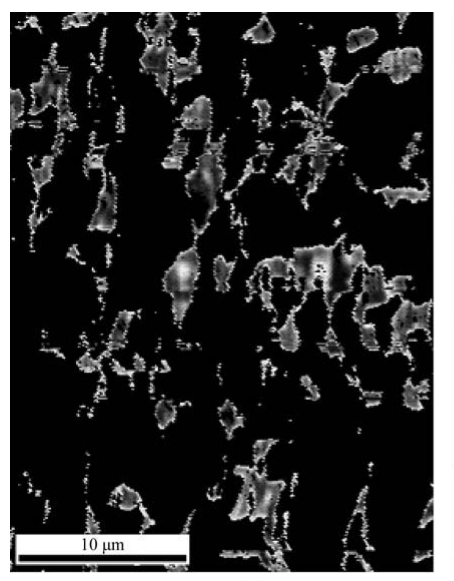

(a)

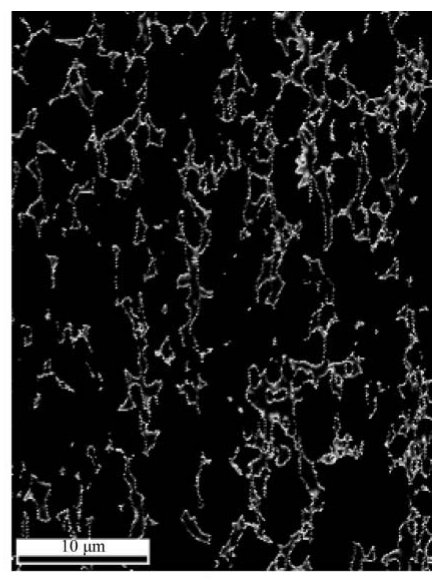

(b)
Figure 6

Image-quality map showing the bainite texture in $(a)$ the A1T1 and $(b)$ the A3T1 samples.

we suppose that the transformed fraction of austenite to proeutectoid ferrite is very small when the cooling is fast enough. Otherwise, if some ferrite forms during cooling, the orientation change of the retained austenite might be more significant. It can be supposed that, during subsequent austempering, the bainite (in the absence of polygonal ferrite) nucleates on the austenite-ferrite interface and the orientation of the product phase coincides with the austenite phase according to the KS relationship. There are clear signs that the main f.c.c. texture components of austenite, i.e. copper, S, Goss

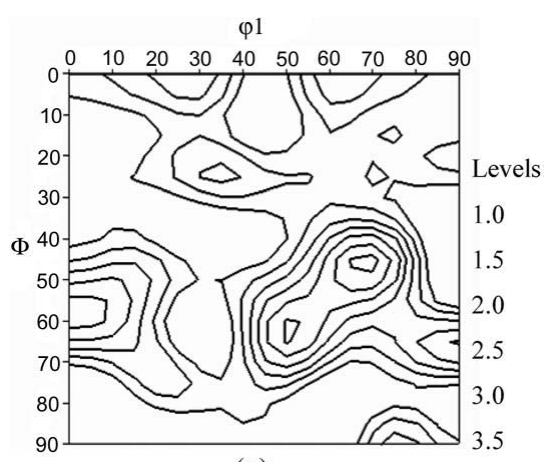

(a)

$\varphi 1$

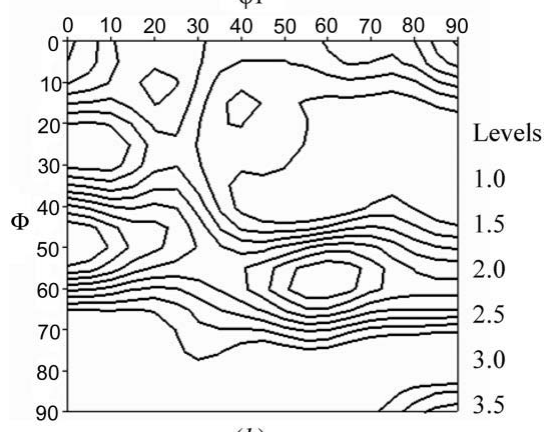

(b)

Figure 7

$\varphi_{2}=45^{\circ}$ sections of ODFs, representing the texture components of highlighted bainite shown in Fig. 6, for $(a)$ the A1T1 and $(b)$ the A3T1 samples. and brass, change mainly to the $\gamma$ - and $\alpha$-fibre components of the b.c.c. bainitic ferrite (Verlinden et al., 2001; De Meyer et al., 2001).

In this study, the bainite after isothermal transformation was separated from the initial pro-eutectoid (polygonal) ferrite by inspection of the image quality of the Kikuchi patterns of b.c.c. crystals (Petrov et al., 2007). The lower image quality of bainite is due to the high dislocation density in the bainitic ferrite laths and it can be distinguished from the polygonal ferrite. Fig. 6 illustrates the image-quality map of bainite for the A1T1 and A3T1 samples. The ODFs corresponding to the highlighted points of Fig. 6 are shown in Fig. 7. The bainite texture was recognized by the $\gamma$-fibre components and also by the Goss component for both samples at this ODF section.

It is important to observe that the weak Goss and copper components of the austenite phase in the A1T1 sample completely transform to bainite and, as shown in Fig. 1(a), that the retained austenite texture is free of these components. Indeed, the lighter cold-rolling reduction leads to a coarse austenite grain size at the intercritical annealing temperature, so that, after transformation to bainite, coarser bainite colonies would form (Fig. 6a). Consequently, according to the retained austenite phase map, a less disperse and larger grain size of retained austenite is observed (Fig. 8a) in sample A1T1. Thus, it may be concluded that the bainite has nucleated on the Goss and copper orientation and all of these austenite grains have completely transformed to bainite. Other austenite orientations, such as the brass and $\mathrm{S}$ components, have only partially transformed and the retained austenite texture includes these orientations.

In contrast with the low cold-rolling reduction, the heavily deformed sample provides a finer austenite grain size, spread over a wide range of orientations, because of the finer recrystallized ferrite grain size and consequently the higher number of austenite nucleation sites. By transformation of this austenite to bainite during the isothermal holding treatment, it is expected that finer bainite colonies will form (Fig. 6b),

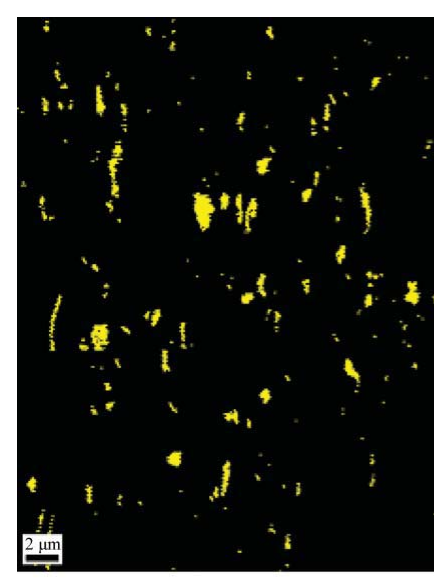

(a)

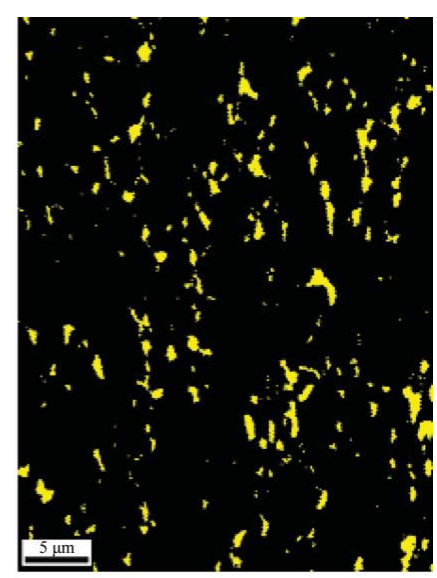

(b)
Figure 8

Retained austenite phase map, showing the size and distribution of retained austenite in $(a)$ the A1T1 and $(b)$ the A3T1 samples 


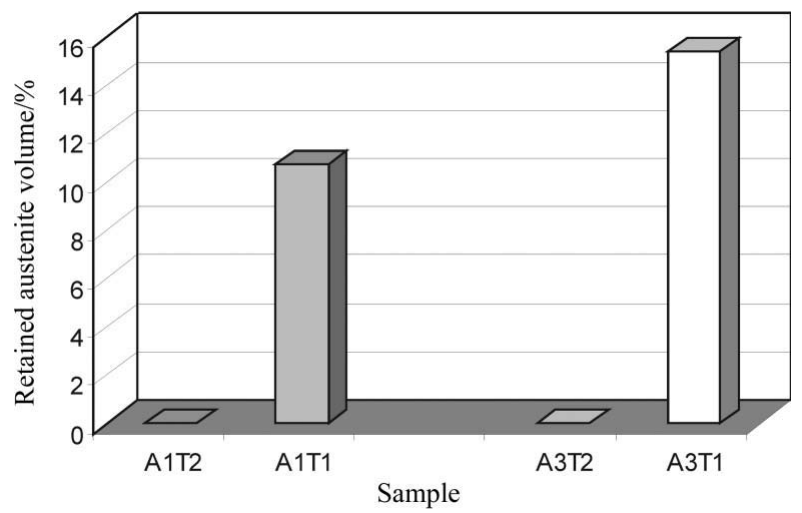

Figure 9

Variation in the volume fraction of retained austenite as a function of cold-rolling reduction.

surrounded by finer and more disperse retained austenite grains (Fig. 8b). Furthermore, this implies that an increased volume fraction of retained austenite is formed compared with the less deformed A1T1 samples. This assumption is confirmed by the measured volume fractions of retained austenite for both rolling reductions (Fig. 9).

For the A3T1 sample, the austenite grains with Goss and copper components start to transform to bainite earlier, similar to the effect observed in the A1T1 sample. However, it seems that, under heavy cold-rolling reduction, the small austenitic grains and the recrystallized polygonal ferrite prevent the completion of the bainitic transformation. Therefore, it is concluded that more austenite with these texture components is retained in the final microstructure, which is confirmed by the experimental observation (Fig. 1b).

\section{Conclusion}

From the results of experimental work carried out on the effect of initial cold rolling on the microtexture development of retained austenite in intercritically annealed TRIP steel, the following conclusions can be drawn:

(a) The main texture components of the retained austenite are along the f.c.c. $\beta$ fibre with components of brass, copper and Goss, and their appearance and intensity depend on the initial degree of cold-rolling reduction.

(b) In the lightly cold-rolled sample, retained austenite grains with copper and Goss orientations are absent from the final microstructure, which indicates that these components of the high-temperature austenite phase transform preferentially to bainite during austempering.

(c) In contrast with the lightly cold-rolled sheets, heavily deformed samples contain retained austenite with all major texture components of the $\beta$ fibre after annealing and austempering. Under these conditions, the bainitic transformation does not complete to consume all copper and Goss components of the austenite. The lower intensity of the brass components for the A3T1 samples compared with the A1T1 sample also shows that there is a selective transformation to bainite of high-temperature austenite with these orientations.
The authors thank the technicians of the laboratory of the Department of Metallurgical and Materials Science, Ghent University, for their assistance in the experimental work. EE acknowledges the staff of the Department of Materials, Semnan University, for their help with the dilatometry tests. EE is also grateful to the Ministry of Science, Research and Technology of the Islamic Republic of Iran for the provision of a PhD course scholarship.

\section{References}

Akbarzadeh, A. (1994). PhD thesis, McGill University, Montreal, Canada.

Baik, S. C., Kim, S., Jin, Y. S. \& Kwon, O. (2001). ISIJ Int. 41, 290-297.

Basuki, A. \& Aernoudt, E. (1999). Scr. Mater. 40, 1003-1008.

De Cooman, B. C. (2004). Curr. Opin. Solid State Mater. Sci. 8, 285 303.

De Cooman, B. C., Barbe, L., Mahieu, J., Krizan, D., Samek, L. \& De Meyer, M. (2004). Can. Metall. Q. 43, 13-24.

De Meyer, M., Kestens, L. \& De Cooman, B. C. (2001). Mater. Sci. Tech. 17, 1353-1359.

De Meyer, M., Vanderschueren, D. \& De Cooman, B. C. (1999). ISIJ Int. 39, 813-822.

Eberle, K., Cantinieaux, P. \& Harlet, Ph. (1999). Ironmaking Steelmaking, 26, 176-181.

Emadoddin, E. \& Akbarzadeh, A. (2005). Mater. Sci. Forum, 495497, 513-517.

Furnémont, Q., Delannay, F. \& Jacques, P. J. (2003). J. Phys. IV Fr. 112, 421-424.

Girault, E., Jacques, P., Ratchev, P., Van Humbeeck, J., Verlinden, B. \& Aernoudt, E. (1999). Mater. Sci. Eng. A, 273-275, 471-474.

Huang, J., Poole, W. J. \& Militzer, M. (2004). Metall. Mater. Trans. A, 35, 3363-3375.

Hutchinson, B., Ryde, L., Lindh, E. \& Tagashira, K. (1998). Mater. Sci. Eng. A, 257, 9-17.

Inagaki, H. (1998). ISIJ Int. 38, 76-82.

Kim, S. J., Lee, C. G., Choi, I. \& Lee, S. (2001). Metall. Mater. Trans. $A, \mathbf{3 2}, 505-514$.

Lee, C. G., Kim, S. J., Lee, T. H. \& Oh, C. S. (2004). ISIJ Int. 44, 737747.

Lee, C. G., Kim, S. J., Oh, C. S. \& Lee, S. (2002). ISIJ Int. 42, 1162 1168.

Lee, C. G., Kim, S. J., Song, B. H. \& Lee, S. (2002). Met. Mater. Int. 8, 435-441.

Luo, H., Zhao, L., Kruijver, S. O., Sietsma, J. \& Van Der Zwaag, S. (2003). ISIJ Int. 43, 1219-1227.

Miller, R. L. (1964). Trans. Am. Soc. Met. 57, 892-899.

Miller, R. L. (1968). Trans. Am. Soc. Met. 61, 592-597.

Petrov, R., Kestens, L. \& Houbaert, Y. (2001). ISIJ Int. 41, 883-890.

Petrov, R., Kestens, L., Wassilkowska, A. \& Houbaert, Y. (2007). Mater. Sci. Eng. A, 447, 285-297.

Pyshmintsev, I. Y., De Meyer, M., De Cooman, B. C., Savray, R. A., Shveykin, V. P. \& Vermeulen, M. (2002). Metall. Mater. Trans. A, 33, 1659-1667.

Ray, R. K. \& Jonas, J. J. (1990). Int. Mater. Rev. 35, 1-36.

Regle, H., Maruyama, N. \& Yoshinaga, N. (2004). Mater. Sci. Forum, 467-470, 11-20.

Ryu, H. B., Speer, J. G. \& Wise, J. P. (2002). Metall. Mater. Trans. A, 33, 2811-2816.

Saleh, M. H. \& Priestner, R. (2001). J. Mater. Proc. Tech. 113, $587-$ 593.

Samajdar, L., Girault, E., Verlinden, B., Aernoudt, E. \& Van Humbeeck, J. (1998). ISIJ Int. 38, 998-1006.

Skalova, L., Divisova, R. \& Jandova, D. (2006). J. Mater. Proc. Tech. 175, 387-392. 


\section{research papers}

Sugimoto, K., Iida, T., Sakaguchi, J. \& Kashima, T. (2000). ISIJ Int. 40, 902-908.

Sugimoto, K., Kanda, A., Kikuchi, R., Hashimoto, S., Kashima, T. \& Ikeda, S. (2002). ISIJ Int. 42, 910-915.

Sugimoto, K., Sakaguchi, J., Iida, T. \& Kashima, T. (2000). ISIJ Int. 40, 920-926.

Takahashi, M. (2003). Nippon Steel Tech. Rep. 88, 1-18.

TexSem Laboratories (2010). TSL OIM. Version 4.6. TexSem Laboratories Inc., Draper, Utah, USA.
Timokhina, I. B., Hodgson, P. D. \& Pereloma, E. V. (2003). Metall. Mater. Trans. A, 34, 1599-1609.

Verlinden, B., Bocher, Ph., Girault, E. \& Aernoudt, E. (2001). Scr. Mater. 45, 909-916.

Walentek, A., Hu, X., Seefeldt, M. \& Van Houtte, P. (2005). Mater. Sci. Forum, 495-497, 369-373.

Wang, L. \& Hsu, T. Y. (2005). Mater. Sci. Forum, 475-479, 179-182. Zaefferer, S., Ohlert, J. \& Bleck, W. (2004). Acta Mater. 52, 2765 2778. 